\title{
Increased vascular expression of iNOS at day but not at night in asthmatic subjects with increased nocturnal airway obstruction
}

\author{
N.H.T. ten Hacken*, D.S. Postma*, G. Drok**, M. Smith**, J. Kraan*, W. Timens**
}

\begin{abstract}
Increased vascular expression of iNOS at day but not at night in asthmatic subjects with increased nocturnal airway obstruction. N.H.T. ten Hacken, D.S. Postma, G. Drok, M. Smith, J. Kraan, W. Timens. (C) ERS Journals Ltd 2000.

ABSTRACT: Nitric oxide production by endothelial cells may have important consequences for the development of airway inflammation as well as for airway obstruction. The present study investigated whether the expression of vascular inducible nitric oxide synthase (iNOS) and endothelial nitric oxide synthase (eNOS) in human bronchi differs between asthmatic and healthy subjects, and whether it shows a circadian rhythm, especially in subjects with increased nocturnal airway obstruction.

Bronchial biopsy samples were taken at 16:00 and 04:00 $\mathrm{h}$ from 13 healthy and 25 asthmatic subjects, 18-45 yrs. Biopsy samples were snap-frozen and double-immunostained for iNOS and eNOS in combination with a common vascular antigen (CD31). The degree of immunopositivity was expressed as a percentage of CD31positive vessels encountered in complete biopsy sections.

Asthmatic subjects showed greater iNOS expression than healthy controls: $23 \pm 15$ versus $7 \pm 17 \%($ mean \pm sD) at $16: 00 \mathrm{~h}(\mathrm{p}<0.001)$ and $19 \pm 15$ versus $8 \pm 11 \%$ at $04: 00 \mathrm{~h}$ $(p<0.05)$. Asthmatic subjects with a fall in forced expiratory volume in one second of $>10 \%$ of the predicted value between 16:00 and 04:00 $\mathrm{h}$ showed greater iNOS expression at 16:00 than at 04:00 h: $32 \pm 16$ versus $20 \pm 13 \%(p<0.05)$. eNOS expression did not differ between healthy controls and asthmatic patients, nor did it differ between 16:00 and 04:00 $\mathrm{h}$.

It is suggested that asthmatic subjects with increased nocturnal airway obstruction demonstrate increased activation of inducible nitric oxide synthase during the day. The resulting nitric oxide production might protect against airway obstruction during the day. However, at night, nitric oxide production is probably insufficient to counterbalance the bronchoconstricting forces.
\end{abstract}

Eur Respir J 2000; 16: 445-451.

Depts. of *Pulmonology and **Pathology, University Hospital Groningen, the Netherlands.

Correspondence: N.H.T. ten Hacken, Dept of Pulmonology, University Hospital Groningen, P.O. Box 30.001, 9700 RB Groningen, The Netherlands. Fax: 31 503619320

Keywords: Asthma

biopsy

endothelial nitric oxide synthase

immunohistology

inducible nitric oxide synthase

nitric oxide

Received: August 31999

Accepted after revision April 252000

This work was supported by a grant from the Netherlands Asthma Foundation, the Stichting Astma Bestrijding and the Jan Kornelis de Cock stichting.
In recent years, there has been extensive interest in the role of nitric oxide in the pathophysiology of asthma [1]. Asthmatic patients show higher levels of exhaled NO than healthy controls, which is thought to be a reflection of the underlying asthmatic airway inflammation $[2,3]$. Increased production of $\mathrm{NO}$ is considered not only a reflection of but also a mediating factor for increased airway inflammation [4-6]. Increased airway inflammation may contribute to narrowing of the airways and increased bronchial hyperresponsiveness $[4,6,7]$. Conversely, NO may cause smooth muscles to relax in a direct way and thus decrease bronchoconstriction [8] and bronchial hyperresponsiveness [9-12]. This dual effect of NO on the patency of the airways has been suggested in several animal studies $[13,14]$. The aim of the present study was to obtain greater insight into the dual effects of NO by investigating the enzymes responsible for NO production in patients with nocturnal and non-nocturnal asthma.

Inducible nitric oxide synthase (iNOS) is one of the enzymes that has been the focus of attention of many researchers, especially because it is modulated by inflam- matory factors. Gradually, the paradigm has evolved that expression of iNOS is upregulated in epithelial and inflammatory cells in asthmatic bronchi $[2,3]$ and that it is responsible for the elevated NO levels measured in exhaled air [2, 3]. However, to date, only one biopsy study on iNOS in asthmatic patients has been published, showing increased expression of iNOS in the epithelium [15]. In contrast to iNOS, relatively little attention has been given to the role of the constitutive synthases (cNOSs), most probably because these are supposed not to be modulated by inflammatory factors. Moreover, the cNOSs are thought to be responsible for the production of only small amounts of NO. However, new findings indicate that iNOS can be present constantly [16], whereas endothelial cNOS (eNOS) can be subject to modest degrees of regulation [17].

Several vascular mechanisms are thought to be important for acute and chronic airway wall inflammation [18]. Interestingly, NO may be one of the mediating factors as it promotes airway blood flow, hyperpermeability and plasma exudation [6, 19-21]. Conversely, NO inhibits the recruitment of inflammatory cells by suppressing 
endothelial adhesion molecules [22-26]. The endothelium itself is able to express both iNOS and eNOS [27], which is important because $\mathrm{NO}$ has a high affinity for haemoglobin. Until now, the close relationship between iNOS and eNOS expression has not been studied in human bronchi.

The present study addressed the variable expression of vascular iNOS and eNOS in the bronchi of asthmatic and healthy subjects. The main questions of this study were as follows. 1) Is the expression of vascular iNOS and eNOS different between asthmatic and healthy subjects? 2) Is there circadian variation in the expression of vascular iNOS and eNOS, especially in subjects with increased nocturnal airway obstruction? In a study on nocturnal asthma, bronchial biopsy samples were obtained at 16:00 and 04:00 h from 13 healthy controls and from 25 asthmatic patients [28]. The presence of vascular iNOS and eNOS, was examined in these samples and day and night levels compared.

\section{Material and methods}

Thirteen healthy volunteers and 25 asthmatic subjects aged 18-45 yrs participated in this study (table 1). Asthmatic subjects were selected on the basis of: a history consistent with asthma; presence of atopy (positive intracutaneous tests against house dust mite or two other aeroallergens), forced expiratory volume in one second (FEV1) $>1.5 \mathrm{~L}$ and $>60 \%$ of the predicted value; provocative concentration of methacholinebromide causing a $20 \%$ fall in FEV1 (PC20 methacholine) methacholinebromide $\leq 9.8 \mathrm{mg} \cdot \mathrm{mL}^{-1}$; PC20 adenosine monophosphate (AMP) $\leq 80 \mathrm{mg} \cdot \mathrm{mL}^{-1}$; and no use of oral corticosteroids within 2 months and no use of inhaled corticosteroids within 1 month before the study. Subjects with a history of smoking within the last 2 yrs or with a respiratory infection within the last 4 weeks were excluded. The study was approved by the Medical Ethics Committee of University Hospital Groningen, and all subjects gave their written informed consent. The participating subjects were further characterized by reversibility of FEV1 (\% pred) and blood eosinophil numbers.

Subjects underwent bronchoscopy at 16:00 and 04:00 h in randomized order, with an interval of 7-14 days. Three

Table 1. - Characteristics of participating subjects

\begin{tabular}{lcc}
\hline & Healthy controls & Asthmatics \\
\hline Male/Female n & $5 / 8$ & $15 / 10$ \\
Age yrs & $32 \pm 8.4$ & $31 \pm 9.1$ \\
Eosinophils $10^{6}$ cells $\cdot \mathrm{mL}^{-1}$ & 0.08 & 0.25 \\
& $(0.03-0.31)$ & $(0.08-0.54)^{* *}$ \\
FEV1 \% pred & $106 \pm 14$ & $93 \pm 13^{* *}$ \\
Reversibility \% pred & $1.5 \pm 2.1$ & $11 \pm 10^{* * *}$ \\
PEF variation \% & $7.5 \pm 3.2$ & $14.8 \pm 8.2^{* * *}$ \\
PC20 methacholine $\mu \mathrm{g} \cdot \mathrm{mL}^{-1}$ & $>9.8$ & 0.54 \\
& & $(0.08-6.61)$ \\
PC20 AMP $\mathrm{mg} \cdot \mathrm{mL}^{-1}$ & $>80$ & 2.80 \\
& & $(0.18-22.8)$ \\
\hline
\end{tabular}

Data are expressed as mean \pm SD or geometric mean (range). ${ }^{+}$: of forced expiratory volume in one second (FEV1) on inhalation of $400 \mu \mathrm{g}$ salbutamol. PEF: peak expiratory flow; PC20: provocative concentration of drug causing a $20 \%$ fall in FEV1; AMP: adenosine monophosphate. $* *, * * *: \mathrm{p}<0.01, \mathrm{p} \leq 0.001$ versus healthy controls. days before the first bronchoscopy, bronchodilators were withheld and peak expiratory flow (PEF) (Mini-Wright) was recorded at 08:00, 12:00, 16:00, 20:00, 24:00, and 04:00 h. PEF variation was defined as: (highest -lowest PEF) / mean of the six daily measurements. Mean PEF variation was calculated as the mean variation over 3 days. Thirty minutes before the 16:00 and 04:00 h bronchoscopy, FEV1 was measured using a calibrated water-sealed spirometer according to standardized guidelines. Asthmatic subjects were arbitrarily divided into subjects with a fall in FEV 1 of $\leq$ and $>10 \%$ pred between 16:00 and 04:00 $\mathrm{h}$.

All bronchoscopy was performed by one experienced investigator (N. ten Hacken) using an Olympus B1 IT10 flexible fibreoptic bronchoscope (Olympus Optical, Tokyo, Japan). Biopsy samples were obtained from the subcarinae of the left or right lower lobe using fenestrated forceps (FB-21C, Olympus), according to American Thoracic Society guidelines [30].

Biopsy samples were mounted in Tissue Tek $\mathbb{R}$ (Sakura, Tokyo, Japan) and snap-frozen by immersion in isopentane $\left(-80^{\circ} \mathrm{C}\right)$. Serial sections were cut at a thickness of $4 \mu \mathrm{m}$. Every twenty-fifth section was stained with Mayer's haematoxylin and eosin. The series with the morphologically best and largest sections were selected for immunostaining. Vessels were double-immunostained using a monoclonal antibody recognizing all vessels in combination with a rabbit polyclonal antibody recognizing iNOS or mouse monoclonal antibody recognizing eNOS, respectively. The primary antibodies were applied as a mixture in one step. Previous validation experiments in the authors' laboratory had demonstrated that applying a mixture produced exactly the same results as using each antibody separately in a twostep method, independent of the sequence of the primary antibodies. Vessels were recognized by anti-CD31 antibodies immunoglobulin G (IgG) 2b isotype, Monosan, Uden, the Netherlands), which were labelled by isotypespecific biotinylated goat anti-mouse IgG2b (Southern Biotechnology Associates, Birmingham, AL, USA) and subsequently by streptavidin conjugated to alkaline phosphatase (DAKO, Glostrup, Denmark) which provided a blue reaction product with Fast Blue BB. iNOS and eNOS were recognized by rabbit polyclonal anti-iNOS and mouse monoclonal (IgG1-isotype) anti-eNOS (Transduction Laboratories, Lexington, KY, USA), respectively. These antibodies were labelled by goat antirabbit antibodies (iNOS) and isotype-specific goat antimouse IgG1 (eNOS) conjugated to peroxidase (SBA), using 3-amino-9ethylcarbazole as a substrate, which results in a reddishbrown reaction product. Negative control sections were used for all subjects by omitting incubation with primary antibodies. Further, results were compared with speciesspecific, isotype-matched nonrelevant antibodies. Positive controls were included by using lung and tonsil resection material from routine surgical procedures.

In the present study, only one antibody was used against each NOS. Selection of these antibodies was based on the general opinion of experts in the field that these antibodies were the best at that time, and on extensive research in the authors' laboratory on the sensitivity and specificity of several other antibodies available at the time [31]. In this pilot study, western blots were performed but were unable to detect significant cross-reactivity of the selected antibodies. Since iNOS positivity of epithelial cells was not found it was attempted to increase the signal in several 
ways: potentiation of the second step using an alkaline phosphatase-antialkaline phosphatase method that was repeated three times, overnight incubation at $4{ }^{\circ} \mathrm{C}$ to include low-affinity receptor binding, incubation of the sections with increasing concentrations of anti-iNOS (1:50,1:20,1:10, and 1:5), and combinations of these three methods. However, none of these attempts improved the signal. More recently, studies of iNOS and eNOS reactivity were performed using formalin-fixed paraffin-embedded biopsy samples from asthmatics, in which it was also not possible to detect reactivity for iNOS in the bronchial epithelium.

Whole sections were examined systematically in a blinded way, using an eye grid, at a magnification of $250 \times$. Vessels were recognized on the basis of morphology and CD31 immunopositivity. Whenever immunopositivity for iNOS or eNOS was also present, this was expressed as a percentage of CD31-positive vessels [32]. Before starting the official counting procedure, 20 sections were examined by two observers on several separate occasions. After reaching acceptable interobserver reproducibility, all sections were quantified twice by the same observer, the mean results for each case being entered for analysis. The mean intraobserver difference (confidence interval) [33] for iNOS was $1.0 \%(-2.2-3.8 \%)$; the mean intraobserver correlation was $0.91(\mathrm{p}<0.01)$. The mean intraobserver difference (confidence interval) for eNOS was: 1.4\% (-1.3$4.1 \%)$; the mean intraobserver correlation was: 0.93 $(\mathrm{p}<0.001)$.

An unpaired t-test was used to compare variables between groups, and a paired t-test to compare 04:00 and $16: 00 \mathrm{~h}$ values within groups, on condition of a normal distribution. Because the percentage of iNOS and eNOS positivity at 16:00 and 04:00 $\mathrm{h}$ showed normal distributions, values are reported as mean \pm SD. Correlations between the percentage of iNOS or eNOS expression and clinical variables were performed using Pearson's rank test, also assuming a normal distribution.

\section{Results}

Vascular inducible and endothelial nitric oxide synthase expression

Expression of iNOS and eNOS on CD31-positive vessels was found to be "patchy" in asthmatic subjects as well as in healthy controls (fig. 1). No differences in the percentages of iNOS- and eNOS- positive vessels were seen between the superficial layers of the submucosa (within $50 \mu \mathrm{m}$ below the basement membrane) and the deeper parts of biopsy samples.
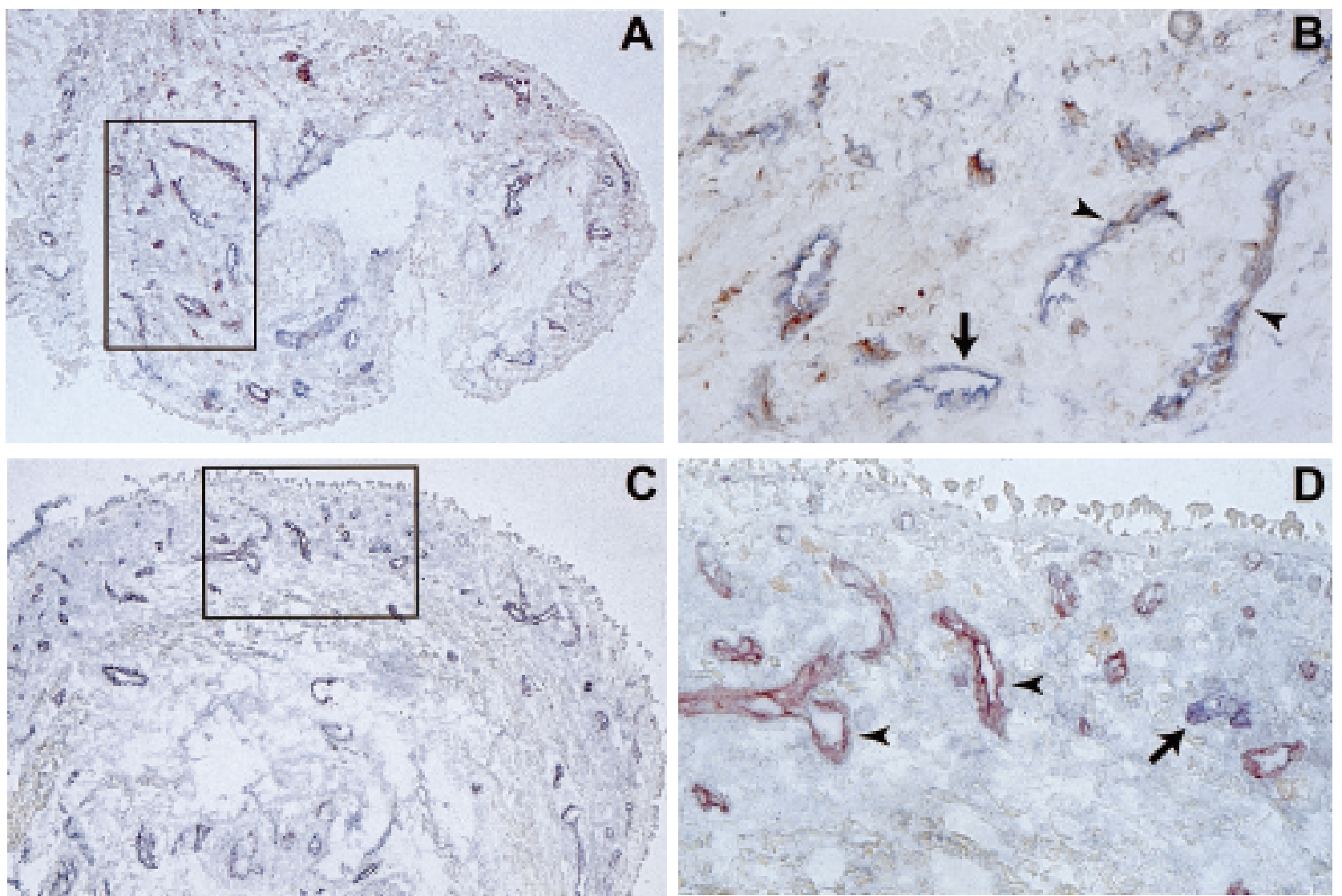

Fig. 1. - A and B) Bronchial biopsy sample from an asthmatic subject, double-immunostained for inducible nitric oxide synthase (iNOS); and C and D) bronchial biopsy sample from another asthmatic subject, double-immunostained for endothelial nitric oxide synthase and CD31 and are labelled by immunoperoxidase (reddish-brown) and CD31 by immunoalkaline phosphatase (blue) Arrow heads: iNOS- or eNOS-positive vessels; arrows: iNOSand eNOS-negative vessels. (Original magnification $\mathrm{A}$ and $\mathrm{C} \times 100, \mathrm{~B}$ and $\mathrm{D}=\times 300$.) 
Inducible nitric oxide synthase expression relative to CD31 expression

iNOS expression was significantly greater in asthmatic subjects than in healthy controls, both at 16:00 and at 04:00 $\mathrm{h}$ (table 2). At 16:00 h, asthmatics with a fall in FEV1 of $>10 \%$ pred between 16:00 and 04:00 h showed greater iNOS expression than asthmatics without such a fall: $32 \pm 16$ versus $19 \pm 13 \%(\mathrm{p}=0.055)$ (fig. 2$)$. Moreover, the former showed greater iNOS expression at 16:00 $\mathrm{h}$ than at 04:00 h: $32 \pm 16$ versus $20 \pm 13 \%(p=0.03)$. iNOS expression at both 16:00 $\mathrm{h}$ and 04:00 $\mathrm{h}$ was not significantly correlated with FEV1 (\% pred), PC20 methacholine, PC20 AMP or number of blood eosinophils.

\section{Endothelial nitric oxide synthase expression relative to CD31 expression}

eNOS expression did not differ significantly between asthmatic subjects and healthy controls (table 2), nor between asthmatics with a fall in FEV1 of $\leq$ versus $>10 \%$ pred between 16:00 and 04:00 h. eNOS expression did not differ significantly between 16:00 and 04:00 h in either group. eNOS expression did not significantly correlate with iNOS expression, nor with 16:00-04:00 h changes in eNOS or iNOS expression. The 16:00-04:00 h change in eNOS expression correlated significantly with the PEF variation measured at home in asthmatic subjects (rho=0.48; $\mathrm{p}=0.03$ ) (fig. 3).

\section{Discussion}

The present study demonstrates that the vascular expression of iNOS is greater in asthmatic subjects than in healthy controls. These results correspond partly with the findings of HAMID et al. [15], who showed greater epithelial expression of iNOS in bronchial biopsy samples from asthmatic subjects. Greater expression of iNOS may lead to greater NO production, which is suggested by in vitro [16] and in vivo findings $[2,3,34]$. Because NO theoretically may lead to airway obstruction as well as airway dilatation, this study focused on patients with a strong and predictable variation in airway diameter, as is observed in patients with nocturnal asthma.

The greater daytime vascular expression of iNOS in asthmatic subjects with increased nocturnal airway obstruction is an interesting finding. It indicates that the immune system of asthmatic subjects with increased nocturnal airway obstruction becomes more activated in the

Table 2. - Vascular inducible (iNOS) and endothelial nitric oxide synthase (eNOS) expression at 16:00 and 04:00 h

\begin{tabular}{lccccc}
\hline & \multicolumn{2}{c}{ Healthy controls } & & \multicolumn{2}{c}{ Asthmatic subjects } \\
\cline { 2 - 3 } \cline { 5 - 6 } & $16: 00 \mathrm{~h}$ & $04: 00 \mathrm{~h}$ & & $16: 00 \mathrm{~h}$ & $04: 00 \mathrm{~h}$ \\
\hline Subjects $\mathrm{n}$ & \multicolumn{3}{c}{13} & & \multicolumn{2}{c}{25} \\
iNOS/CD31 \% & $6.6 \pm 17$ & $8.0 \pm 11$ & & $23 \pm 15^{* *}$ & $19 \pm 15^{*}$ \\
eNOS/CD31 \% & $21 \pm 22$ & $33 \pm 27$ & & $28 \pm 30$ & $29 \pm 29$ \\
\hline
\end{tabular}

Data are presented as mean \pm SD. There were no significant differences between day and night; $* * *: \mathrm{p}<0.05, \mathrm{p}<0.01$ versus healthy controls.

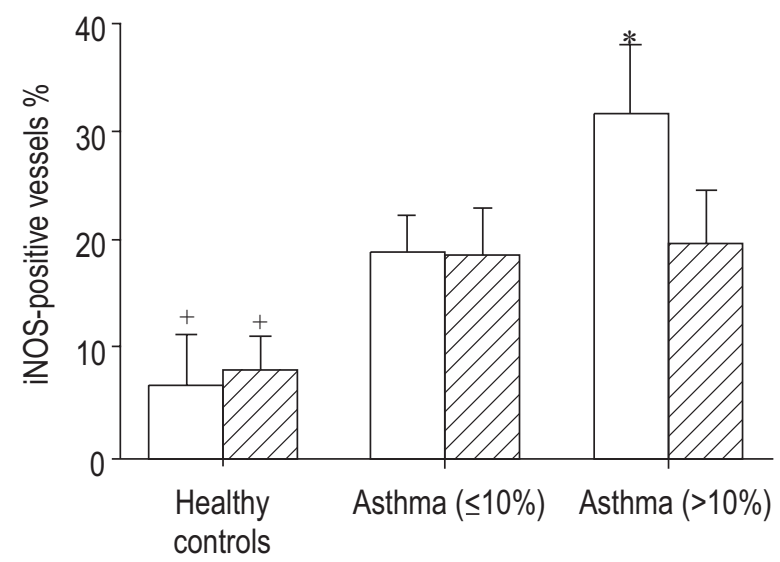

Fig. 2. - Vascular expression of inducible nitric oxide synthase (iNOS) at 16:00 $\mathrm{h}(\square)$ and 04:00 $\mathrm{h}(\mathbb{Z})$ of 13 healthy controls and 16 asthmatic subjects with 16:00-04:00 $\mathrm{h}$ fall in forced expiratory volume in one second (FEV1 of $\leq 10 \%$ pred) and 9 asthmatic subjects with 16:0004:00 fall in FEV1 of $>10 \%$ pred. Data are presented as mean \pm SEM. *: $\mathrm{p}<0.05$ versus all other asthmatic subjects; ${ }^{+}: \mathrm{p}<0.05$ versus all asthmatic subjects at the same time point.

day than at night, in contrast to asthmatic subjects without increased nocturnal airway obstruction. This is in line with the findings of OOSTERHOFF et al. [35], who demonstrated a daytime increase in the CD11b expression of alveolar macrophages in subjects with nocturnal asthma, correlating with circadian PEF variation. This is also in line with the higher daytime levels and decreasing night-time levels of $\mathrm{NO}$ in the exhaled air of subjects with nocturnal asthma [36]. In contrast, two other studies demonstrated more inflammation at night than in the day in patients with nocturnal asthma [37, 38]. However, this increased inflammation was demonstrated in bronchoalveolar lavage fluid and transbronchial biopsy samples, particularly in the peripheral airways and lung parenchyma. Two mechanisms may explain the seeming discrepancy between the lower levels of iNOS expression and the greater degree of airway obstruction at night in the present study. First, inhalation of inflammatory triggers (such as allergens) leads to an increased daytime NOS induction. At night, these triggers are inhaled to a lesser extent and

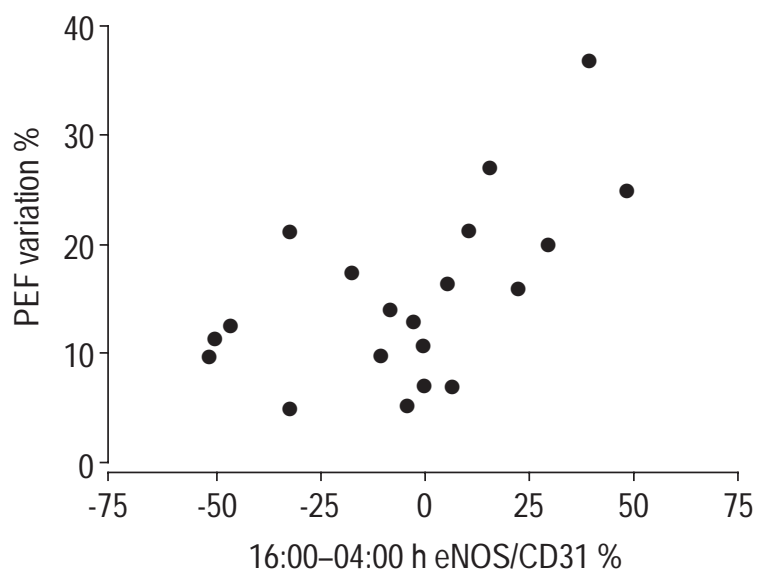

Fig. 3. - Significant positive correlation between 16:00-04:00 h difference in expression of endothelial nitric oxide synthase (eNOS) and peak expiratory flow $(\mathrm{PEF})$ variation in asthmatic patients $(\mathrm{rho}=0.48 ; \mathrm{p}=0.03)$. 
iNOS expression becomes downregulated. In contrast to iNOS expression, the increased airway inflammation is not resolved within $12 \mathrm{~h}$ and is still present at night [28]. Obviously, this explanation assumes that induction of iNOS is not completely in phase with induction of airway inflammation. Furthermore, the authors speculate that daytime NO production may be sufficient to counterbalance the bronchoconstricting forces of airway inflammation, but that this bronchoprotective mechanism may be insufficient at night.

The present study also demonstrated that expression of eNOS is not significantly different between bronchial biopsy samples from healthy and asthmatic subjects. It was expected that lesser eNOS expression would be found in biopsy samples from asthmatic subjects for two reasons. First, tumour necrosis factor- $\alpha$, a pro-inflammatory cytokine involved in asthmatic airway inflammation [39], is known to downregulate eNOS expression by shortening its half-life [40, 41]. Secondly, in asthmatic airway inflammation, vascular expression of iNOS may be strongly upregulated, and, as a consequence, large amounts of NO may suppress vascular eNOS activity [42]. Therefore, an inverse relationship between eNOS and iNOS expression was expected, but there was no such tendency. In addition, a significant but weak correlation was found between 16:00-04:00 $\mathrm{h}$ change in eNOS expression and PEF variation measured at home. These findings may be partly explained by asthmatic patients with large PEF variations suffering from increased nocturnal airway obstruction, hyperinflation and "auto-positive end-expiratory pressure" auto-PEEP, leading to lower levels of submucosal bloodflow, shear stress and night-time eNOS expression. Conversely, considering the relatively low rho, it is possible that the correlation between 16:0004:00 h change in eNOS expression and PEF variation is merely a chance occurrence.

Further, it was questioned why circadian variations in iNOS expression are related to 16:00-04:00 h FEV1, and circadian variations in eNOS expression to PEF variation. One explanation may be that the circadian variations in eNOS expression are particularly dependent on intrinsic (endogenous) factors, which are better reflected by repeated measurements of PEF on 3 subsequent days. In contrast, the circadian variations in iNOS expression could be more dependent on extrinsic (exogenous) factors, which are better reflected by measurements of airway obstruction on 1 day. A second explanation might be that the participating subjects were sleeping in the hospital before the 04:00 $\mathrm{h}$ bronchoscopy, but were outside the hospital before the 16:00 h bronchoscopy. OOSTERHOFF et al. [43] have shown already that measurements of nocturnal airway obstruction are lower in hospital than at home, probably because subjects are less exposed to house dust in hospital.

Adequate immunohistological detection of iNOS and eNOS expression is quite difficult and hindered by the variable specificity and sensitivity of the available (including commercially available) antibodies [31]. This is probably the reason that only a few reports have been published on this topic, despite the great scientific interest in this field of research. In this study, two antibodies were chosen out of a set of 10 commercially available antiNOS, principally because they showed the greatest sensitivity and specificity in specimen of human bronchi
[31]. These results may not completely agree with those of other papers $[15,27,44-46]$ since the specific set of antibodies used in the present study may be different from those used by others. It should be noted that at least some studies have used noncommercial antibodies, the specificity and sensitivity of which are difficult to verify. A further difference may be caused by the fact that fresh frozen tissue techniques were used in the present study. Moreover, lung tissue (biopsy samples) from subjects with stable disease that were not on a mechanical ventilator were investigated. For example, in contrast to the results of HAMID et al. [15] no significant anti-iNOS signal could be detected in epithelial cells. It was attempted to increase the signal in several ways (see Materials and methods section), but, in contrast to the results of HAMID et al. [15] positivity of the epithelial cells was only very scarce, despite all attempts. Because iNOS positivity of inflammatory cells and vessels was readily clear, the results were trusted and the iNOS negativity of the epithelium was accepted. More recently, studies of iNOS and eNOS reactivity using formalin-fixed paraffin-embedded biopsy samples from asthmatics were performed in which reactivity for iNOS could not be detected in the bronchial epithelium.

The authors would like to emphasize that for both iNOS and eNOS expression, immunohistological detection of NOS reflects its presence and not its activity per se. Inflammatory factors theoretically may change its activity without affecting its level of expression. In addition, inflammatory factors (including high levels of NO) may desensitize the NO receptor guanylate cyclase or decrease L-arginine availability. Therefore, it is recommended that both the presence and activity of NOS are determined in future studies.

It is concluded that asthmatic airway inflammation is accompanied by increased expression of vascular inducible nitric oxide synthase. It has been demonstrated that the expression of vascular endothelial nitric oxide synthase is not changed in asthma, and that there is no relationship between inducible nitric oxide synthase and endothelial nitric oxide synthase expression. Subjects with increased nocturnal airway obstruction show greater daytime expression of vascular inducible nitric oxide synthase. The dual effect of the resulting nitric oxide release may, besides the damaging effects, also be responsible for relatively less daytime bronchoconstriction. At night, nitric oxide production may be insufficient to counterbalance the bronchoconstricting forces.

Acknowledgements. The authors thank R. Douma, S. Rutgers, and R. Meijer for their assistance during bronchoscopy at night.

\section{References}

1. Koshland DE Jr. The molecule of the year. Science 1992; 258: 1861-1861.

2. Alving K, Weitzberg E, Lundberg JM. Increased amount of nitric oxide in exhaled air of asthmatics. Eur Respir $J$ 1993; 6: 1368-1370.

3. Kharitonov SA, Yates D, Robbins RA, Logan-Sinclair R, 
Shinebourne EA, Barnes PJ. Increased nitric oxide in exhaled air of asthmatic patients. Lancet 1994; 343: 133135.

4. Barnes PJ, Liew FY. Nitric oxide and asthmatic inflammation. Immunol Today 1995; 16: 128-130.

5. Barnes PJ, Belvisi MG. Nitric oxide and lung disease. Thorax 1993; 48: 1034-1043.

6. Barnes PJ. NO or no NO in asthma? Thorax 1996; 51: 218-220.

7. Nijkamp FP, Folkerts G. Nitric oxide and bronchial hyperresponsiveness. Arch Int Pharmacodyn Ther 1995; 329: 81-96.

8. Hogman M, Frostell CG, Hedenstrom H, Hedenstierna G. Inhalation of nitric oxide modulates adult human bronchial tone. Am Rev Respir Dis 1993; 148: 1474-1478.

9. Hogman M, Frostell C, Arnberg H, Hedenstierna G. Inhalation of nitric oxide modulates methacholine-induced bronchoconstriction in the rabbit. Eur Respir J 1993; 6: 177-180.

10. Kacmarek RM, Ripple R, Cockrill BA, Bloch KJ, Zapol WM, Johnson DC. Inhaled nitric oxide. A bronchodilator in mild asthmatics with methacholine-induced bronchospasm. Am J Respir Crit Care Med 1996; 153: 128-135.

11. Ricciardolo FL, Geppetti P, Mistretta A, et al. Randomised double-blind placebo-controlled study of the effect of inhibition of nitric oxide synthesis in bradykinininduced asthma. Lancet 1996; 348: 374-377.

12. De Gouw HWFM, Grunberg K, Schot R, Kroes ACM, Dick EC, Sterk PJ. The relationship between exhaled Nitric Oxide and airway hyperresponsiveness following experimental rhinovirus infection in asthmatic subjects. Eur Respir J 1998; 11: 126-132.

13. Folkerts G, Verheyen AK, Geuens GM, Folkerts HF, Nijkamp FP. Virus-induced changes in airway responsiveness, morphology, and histamine levels in guinea pigs. Am Rev Respir Dis 1993; 147: 1569-1577.

14. Schuiling M, Meurs H, Zuidhof AB, Venema N, Zaagsma $\mathrm{J}$. Dual action of iNOS derived nitric oxide in allergeninduced airway hyperreactivity in conscious, unrestrained guinea pigs. Am J Respir Crit Care Med 1998; 158: 1442-1449.

15. Hamid Q, Springall DR, Riveros-Moreno $\mathrm{V}$, et al. Induction of nitric oxide synthase in asthma. Lancet 1993; 342: 1510-1513.

16. Guo FH, De Raeve HR, Rice TW, Stuehr DJ, Thunnissen FB, Erzurum SC. Continuous nitric oxide synthesis by inducible nitric oxide synthase in normal human airway epithelium in vivo. Proc Natl Acad Sci USA 1995; 92: 7809-7813.

17. Harrison DG, Sayegh H, Ohara Y, Inoue N, Venema RC. Regulation of expression of the endothelial cell nitric oxide synthase. Clin Exp Pharm Physiol 1996; 23: 251255.

18. Wanner A. Vascular mechanisms in asthma. In: Busse WW, Holgate ST, eds. Asthma and Rhinitis. Boston, Blackwell Scientific Publications Inc., 1995, pp. 764776.

19. Kuo HP, Liu S, Barnes PJ. The effect of endogenous nitric oxide on neurogenic plasma exudation in guinea-pig airways. Eur J Pharmacol 1992; 221: 385-388.

20. Ialenti A, Ianaro A, Moncada S, Di Rosa M. Modulation of acute inflammation by endogenous nitric oxide. Eur $J$ Pharmacol 1992; 211: 177-182.

21. Alving K, Fornheim C, Weitzberg E, Lundberg JM. Nitric oxide mediates cigarette smoke-induced vasodilatory responses in the lung. Acta Physiol Scand 1992; 146: 407408.
22. De Caterina R, Libby P, Peng HB, et al. Nitric oxide decreases cytokine-induced endothelial activation. Nitric oxide selectively reduces endothelial expression of adhesion molecules and proinflammatory cytokines. $J$ Clin Invest 1995; 96: 60-68.

23. Davenpeck KL, Gauthier TW, Lefer AM. Inhibition of endothelial-derived nitric oxide promotes P-selectin expression and actions in the rat microcirculation. Gastroenterology 1994; 107: 1050-1058.

24. Kubes P, Kurose I, Granger DN. NO donors prevent integrin-induced leukocyte adhesion but not P-selectindependent rolling in postischemic venules. Am J Physiol 1994; 267: H931-H937.

25. Kubes P, Suzuki M, Granger DN. Nitric oxide: an endogenous modulator of leukocyte adhesion. Proc Natl Acad Sci USA 1991; 88: 4651-4655.

26. Gaboury J, Woodman RC, Granger DN, Reinhardt P, Kubes P. Nitric oxide prevents leukocyte adherence: role of superoxide. Am J Physiol 1993; 265: H862-H867.

27. Kobzik L, Bredt DS, Lowenstein CJ, et al. Nitric oxide synthase in human and rat lung: immunocytochemical and histochemical localization. Am J Respir Cell Mol Biol 1993; 9: 371-377.

28. Ten Hacken NHT, Timens W, Smith M, Drok G, Kraan J, Postma DS. Increased peak expiratory flow variation in asthma: severe persistent increase but not nocturnal worsening of airway inflammatory cells. Eur Respir J 1998; 12: 546-550.

29. Quanjer PhH, Tammeling GJ, Cotes JE, Pedersen OF, Peslin R, Yernault J-C. Lung Volumes and Forced Ventilatory Flows. Report Working Party Standardization of Lung Function Tests European Community for Steel and Coal. Official Statement of the European Respiratory Society. Eur Respir J 1993; 6 (Suppl. 16): 5-40.

30. National Heart, Lung and Blood Institute Workshop summaries: summary and recommendations of a workshop on the investigative use of fiberoptic bronchoscopy and bronchoalveolar lavage in asthmatics. Am Rev Respir Dis 1985; 132: 180-182.

31. Coers W, Timens W, Kempinga C, Klok PA, Moshage H. Specificity of antibodies to nitric oxide synthase isoforms in human, guinea pig, rat, and mouse tissues. $J$ Histochem Cytochem 1998; 46: 1385-1392.

32. Ten Hacken NHT, Postma DS, Bosma F, et al. Vascular adhesion molecules in nocturnal asthma: a possible role for VCAM in ongoing airway wall inflammation. Clin Exp Allergy 1998; 28: 1518-1525.

33. Bland JM, Altman DG. Statistical methods for assessing agreement between two methods of clinical measurement. Lancet 1986; 1: 307-310.

34. Yates DH, Kharitonov SA, Robbins RA, Thomas PS, Barnes PJ. Effect of a nitric oxide synthase inhibitor and a glucocorticosteroid on exhaled nitric oxide. Am J Respir Crit Care Med 1995; 152: 892-896.

35. Oosterhoff Y, Hoogsteden HC, Rutgers B, Kauffman HF, Postma DS. Lymphocyte and macrophage activation in bronchoalveolar lavage fluid in nocturnal asthma. $A m J$ Respir Crit Care Med 1995; 151: 75-81.

36. Georges GC, Silkoff PE, Martin RJ. Nocturnal asthmatics exhibit circadian variability in exhaled nitric oxide. $A m J$ Respir Crit Care Med 1998; 157: A612.

37. Martin RJ, Cicutto LC, Smith HR, Ballard RD, Szefler SJ. Airways inflammation in nocturnal asthma. Am Rev Respir Dis 1991; 143: 351-357.

38. Kraft M, Djukanovic R, Wilson S, Holgate ST, Martin RJ. Alveolar tissue inflammation in asthma. Am J Respir Crit Care Med 1996; 154: 1505-1510. 
39. Kips JC, Tavernier JH, Joos GF, Peleman RA, Pauwels RA. Review. The potential role of tumor necrosis factor- $\alpha$ in asthma. Clin Exp Allergy 1993; 23: 247-250.

40. Nishida K, Harrison DG, Navas JP, et al. Molecular cloning and characterization of the constitutive bovine aortic endothelial cell nitric oxide synthase. J Clin Invest 1992; 90: 2092-2096.

41. Yoshizumi M, Perrella MA, Burnett JC Jr, Lee ME. Tumor necrosis factor downregulates an endothelial nitric oxide synthase mRNA by shortening its half-life. Circ Res 1993; 73: 205-209.

42. Nijkamp FP, Folkerts G. Nitric oxide and bronchial reactivity. Clin Exp Allergy 1994; 24: 905-914.

43. Oosterhoff Y, Koëter GH, de Monchy JGR, Postma DS.
Circadian variation in airway responsiveness to metacholine, and AMP in atopic asthmatic subjects. Am Rev Respir Dis 1993; 147: 512-517.

44. Tracey WR, Xue C, Klinghofer V, et al. Immunochemical detection of inducible NO synthase in human lung. Am J Physiol 1994; 266: L722-L727.

45. Warner RL, Paine R, Christensen PJ, et al. Lung sources and cytokine requirements for in vivo expression of inducible nitric oxide synthase. Am J Respir Cell Mol Biol 1995; 12: 649-661.

46. Watkins DN, Peroni DJ, Basclain KA, Garlepp MJ, Thompson PJ. Expression and activity of nitric oxide synthases in human airway epithelium. Am J Respir Cell Mol Biol 1997; 16: 629-639. 